\title{
Adsorption of carbendazim pesticide on plasmonic nanoparticles studied by surface-enhanced Raman scattering
}

\author{
L.N. Furini ${ }^{\text {a }}$, C.J.L. Constantino ${ }^{\text {a }}$, S. Sanchez-Cortes ${ }^{\text {b }}$, J.C. Otero ${ }^{\text {, }}$, I. López-Tocón ${ }^{\text {c,* }}$ \\ ${ }^{a}$ FCT, Universidade Estadual Paulista, Presidente Prudente, SP, Brazil \\ ${ }^{\mathrm{b}}$ Instituto de Estructura de la Materia, CSIC, Serrano 121, E-28006 Madrid, Spain \\ ${ }^{\mathrm{c}}$ Department of Physical Chemistry, Faculty of Science, University of Málaga, Unidad Asociada CSIC, E-29071 Málaga, Spain
}

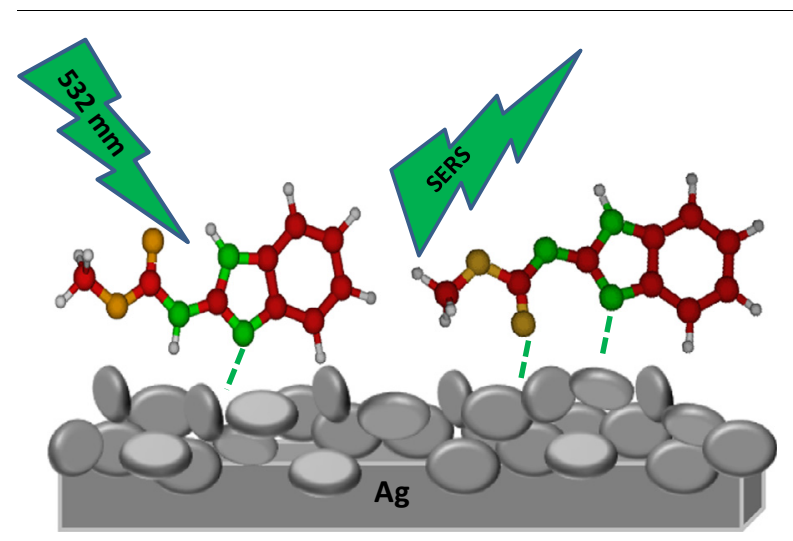

\section{A R T I C L E I N F O}

\section{Article history:}

Received 9 June 2015

Revised 18 November 2015

Accepted 20 November 2015

Available online 21 November 2015

\section{Keywords:}

SERS spectroscopy

Adsorption on colloidal suspensión

Carbendazim

\section{A B S T R A C T}

Surface-Enhanced Raman Spectra (SERS) of methyl N-(1H-benzimidazol-2-yl)carbamate (MBC), usually named carbendazim, have been recorded on silver colloids at different $\mathrm{pH}$ values. In order to identify the neutral, protonated or deprotonated species of MBC that originate the SERS, the vibrational wavenumbers of these three isolated forms and linked to a silver atom have been predicted by carrying out DFT calculations. The results indicate that the active SERS species in the studied $\mathrm{pH}$ range correspond to the neutral MBC and its deprotonated ion in the amidate form. According to theoretical calculations, neutral $\mathrm{MBC}$ is linked to the metal through the imidazolic nitrogen atom, while the deprotonated MBC could be linked through the imidazolic nitrogen together with the amidic nitrogen atom or the carbonyl oxygen atom. Both adsorbed species, neutral and deprotonated, have the benzimidazolic ring orientated almost perpendicular to the silver surface and no molecular reorientation has been detected. $\mathrm{pH}$ of the bulk controls the relative abundance of the neutral $\mathrm{MBC}$ and its amidate anion which can be monitored through the intensities of the SERS bands recorded at about 1230 and $1270 \mathrm{~cm}^{-1}$. These two key bands correspond to the in-plane $\mathrm{NH}$ deformation of amidic and imidazolic groups, respectively.

(c) 2015 Elsevier Inc. All rights reserved.

\footnotetext{
* Corresponding author.

E-mail address: tocon@uma.es (I. López-Tocón).
}

\section{Introduction}

Benzimidazole derivatives are heterocyclic compounds of great interest for their technological [1], medical [2] and biological [3] 
applications. Despite the usefulness of these compounds as fungicides and pesticides of broad-spectrum efficacy [4], some of them are classified as pollutants by European Union establishing their concentration limit in different samples. This is the case of methyl $\mathrm{N}$-(1H-benzimidazol-2-yl)carbamate (MBC), usually named carbendazim. $M B C$ is a systemic fungicide, white powder, with very low solubility in water $\sim 6.11 \mathrm{mg} / \mathrm{L}$. It has two $\mathrm{p} K_{\mathrm{a}}\left(\mathrm{p} K_{\mathrm{a} 1}=4.5\right.$ and $\left.\mathrm{p} K_{\mathrm{a} 2}=10.6\right)$ controlling the relative abundance of protonated $\left(\mathrm{MBC}^{+}\right)$, neutral $\left(\mathrm{MBC}^{0}\right)$ and deprotonated $\left(\mathrm{MBC}^{-}\right)$forms in aqueous solution, depending on the $\mathrm{pH}$ (Fig. 1) [5].

Several analytical methods have been proposed to identify and quantify the presence of environmental pollutants [6,7], as for example, the spectroscopic technique Surface-Enhanced Raman Scattering (SERS) $[8,9]$. SERS is nowadays used for sensitive and selective molecular identification due to the giant electromagnetic (EM) enhancement of the Raman signal induced by localized plasmon resonances in nanostructured noble metal surfaces [10,11]. This huge enhancement provide strong Raman signals from very insoluble compounds such as MBC [5] and allows, for instance, to record the spectra of hydrophobic molecules in aqueous solution at trace level by using molecular hosts of specific analytes such as viologen dications [9,12] or cyclodextrins [13] among others.

Beside analytical applications as chemical sensor, SERS is also a powerful tool to gain insight into the nature of the metal-adsorbate hybrid, the bonded molecular species and its chemical interaction with the metal nanostructure [14-16]. SERS spectra of simple molecules related to MBC such as benzimidazole (BIZ) [16] and imidazole (IZ) [15] have been previously studied. In the case of BIZ two different types of adsorption are proposed depending on the $\mathrm{pH}$, through the $\pi$-electrons of the aromatic ring at neutral $\mathrm{pH}$ or through the protonated nitrogen atom at acidic $\mathrm{pH}$ that assembles a strong ionic pair with chlorine anion [16]. A similar change in the adsorption was found in the case of cyanide anion where a molecular reorientation from perpendicular to parallel adsorption occurs when the cyanide concentration is lowered [17]. Even in the case of acidic $\mathrm{pH}$, the adsorption through deprotonated nitrogen cannot be discarded given the strong chemical interaction between the lone pair of the heteroatom and the metal as well as the effective $\mathrm{pH}$ in the interface of a nanometric environment which can be far apart from the bulk values [18].

$\mathrm{MBC}$ is a much more complex adsorbate given that three different chemical species have to be considered depending on the $\mathrm{pH}$ : the neutral molecule $\left(\mathrm{MBC}^{0}\right)$ and the protonated $\left(\mathrm{MBC}^{+}\right)$and the deprotonated $\left(\mathrm{MBC}^{-}\right)$charged species. Both ionic forms are stabilized by resonance because of the positive or negative charge can be delocalized along the aromatic heterocyclic ring and the carbamate group (Fig. S1 in Supplementary Material). This effect slightly increases the basicity of the imidazolic nitrogen $\left(\mathrm{p} K_{\mathrm{a} 1}=4.5\right)$ with respect to other compounds with $\mathrm{sp}^{2}$ hybridization [19] although remains less basic than imidazole $\left(\mathrm{p} K_{\mathrm{a}}=7.0\right)$, aliphatic amines $\left(\mathrm{p} K_{\mathrm{a}}=10-11\right)$ or ammonia $\left(\mathrm{p} K_{\mathrm{a}}=9.24\right)$. On the other hand, the amidic nitrogen atom located in the carbamate group is slightly more acid $\left(\mathrm{p} K_{\mathrm{a} 2}=10.6\right)$ than aliphatic amides $\left(\mathrm{p} K_{\mathrm{a}}=14-15\right)$ [19].

This work is mainly focused on the study of the effect of the $\mathrm{pH}$ in the coordination of a complex molecular system like MBC on metallic plasmonic surfaces by means of SERS in order to identify the adsorbed species and the specific interacting center with the metal. In this way, SERS spectra of $10^{-5} \mathrm{~mol} / \mathrm{L} \mathrm{MBC}$ have been recorded on silver sols at several $\mathrm{pH}$ values ranging from $\mathrm{pH}=2$ up to 12 . The analysis of the results has been carried out with the help of Density Functional Theory (DFT) calculations which have proved once again their usefulness in the spectral interpretation.

\section{Methods}

All reagents and $\mathrm{MBC}$ were purchased from Sigma-Aldrich. Stock solutions $\left(10^{-3} \mathrm{~mol} / \mathrm{L}\right)$ of $\mathrm{MBC}$ were prepared with ethanol (100\%) provided by VWR, Prolab. Silver sols and aqueous solutions were prepared with water from Milli-Q system $(18.2 \mathrm{M} \Omega \mathrm{cm}$ resistivity).

\subsection{Preparation of Ag nanoparticles and SERS measurements}

$\mathrm{Ag}$ nanoparticles (AgNPs) were prepared by reducing an aqueous solution of silver nitrate $\left(10^{-2} \mathrm{~mol} / \mathrm{L}\right)$ with hydroxylamine hydrochloride $\left(1.66 \times 10^{-3} \mathrm{~mol} / \mathrm{L}\right)$ in alkaline medium $(300 \mu \mathrm{L}$ $\mathrm{NaOH} 1.0 \mathrm{~mol} / \mathrm{L}$ ) under vigorous stirring according to the procedure described elsewhere [20,21]. Other reducing agents such as citrate and $\mathrm{NaBH}_{4}$ can be alternatively used to obtain colloidal suspensions, but it has been shown that the NPs obtained by using hydroxylamine show a more uniform distribution of size and shape and no interferences from the remaining oxidation products are detected [22]. AgNPs were characterized by the resonances of metallic plasmons in the UV-VIS spectra, showing a maximum at about $410 \mathrm{~nm}$ with an average FWHM of $80 \mathrm{~nm}$, and by SEM (Fig. S2 in Supplementary Material). Although the NPs are partially aggregated, there are no large clusters and the isolated NP diameter is of ca. $50 \mathrm{~nm}$. This size is similar to that measured by dynamic light scattering, $54 \mathrm{~nm}$. The zeta potential has been also measured yielding a value of $-30.5 \mathrm{mV}$. Both parameters (size and zeta potential) agree quite well with the characteristic values of electrostatically stabilized sols [23]. A NanoBrook ZetaPALS analyzer with a $35 \mathrm{~mW}$ red diode laser, nominal $640 \mathrm{~nm}$ wavelength, has been employed to measure the diameter and the zeta potential of AgNPs and a Hitachi S-4800 FESEM instruments for obtaining SEM images.

Different procedures to prepare the final samples have been checked in order to optimize the SERS signal/noise ratio. AgNPs colloids were activated by adding $40 \mu \mathrm{L} \mathrm{KNO}_{3}(0.5 \mathrm{~mol} / \mathrm{L})$ to $960 \mu \mathrm{L}$ of AgNPs in a $1 \mathrm{~cm} \times 1 \mathrm{~cm}$ cuvette. The final pH of the colloid was adjusted by adding $5 \mu \mathrm{L} \mathrm{HNO}_{3}(1.0 \mathrm{~mol} / \mathrm{L})$ for obtaining $\mathrm{pH}=2$, and $0.5,1,1.5$ and $5 \mu \mathrm{L} \mathrm{NaOH}$ of $0.5,1.0,1.0$ and $2.0 \mathrm{~mol} / \mathrm{L}$, respectively, for obtaining the corresponding $\mathrm{pH}$ of $6,8,10$ and 12 , respectively. The pre-aggregation induced by $\mathrm{KNO}_{3}$ leads to a slight change of the color as well as an enhancement of the plasmon absorption at higher wavelengths as described in Supplementary Material. Finally, an aliquot of $10 \mu \mathrm{L}$ was removed from the mixture and $10 \mu \mathrm{L}$ of $\mathrm{MBC}$ solution $\left(10^{-3} \mathrm{~mol} / \mathrm{L}\right)$ was added in

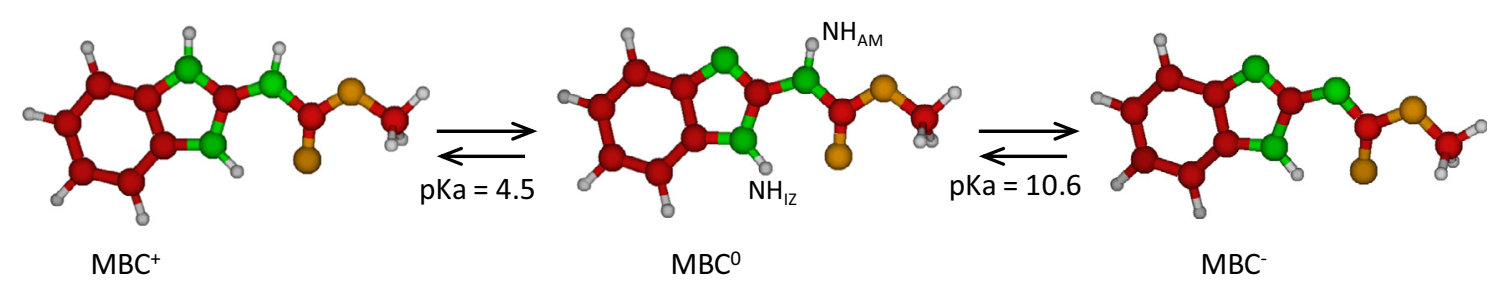

Fig. 1. B3LYP/6-31G* optimized structures of different chemical species of MBC that can exist in aqueous solution depending on the pH. 
order to keep the volume in $1000 \mu \mathrm{L}$. The final MBC concentration was $10^{-5} \mathrm{~mol} / \mathrm{L}$ in all experiments. The $\mathrm{pH}$ values have been measured by $\mathrm{pH}$-indicator strips (MColorpHast, Merck) after adding $\mathrm{MBC}$ molecule. The uncertainty of the measured $\mathrm{pH}$ is estimated to be $\pm 0.5(\mathrm{pH}=5-10)$ or $\pm 1(\mathrm{pH}=0-5$ and $10-14)$. pH has a minimal effect on the stability of the sols in the studied range and the ionic strength remains almost kept constant in all the samples. The stability of the colloid is discussed within Supplementary Material (Figs. S3 and S4).

Raman spectra were obtained using a micro-Raman inVia Renishaw spectrograph, equipped with an electrically cooled CCD camera, under $532 \mathrm{~nm}$ excitation and diffraction grating of $1800 \mathrm{l} / \mathrm{mm}$. The laser power reaching the sample was about $2.0 \mathrm{~mW}$ and the spectral resolution was set to $2 \mathrm{~cm}^{-1}$. Raman spectrum of powder was recorded using the $785 \mathrm{~nm}$ exciting line to avoid fluorescence emission. Although absolute SERS intensity can slightly vary on a particular record, the relative SERS intensity of the bands keeps constant. SERS spectra have been repeated several times under the same experimental conditions in order to check the reproducibility of the intensity ratio of the key bands at 1230 and $1270 \mathrm{~cm}^{-1}$ and estimating a reproducibility similar to that found in the previous work (ca. <20\% [9]).

UV/Vis spectra have been recorded on a Cintra 5 double beam spectrophotometer dotted with Tungsten-halogen and deuterium lamps and $1.5 \mathrm{~nm}$ slit width. The samples were prepared in the same way to that mentioned for recording SERS spectra. The only difference is that the sample $(1 \mathrm{~mL})$ was diluted with $2 \mathrm{~mL}$ of ultrapure water (Milli-Q system) in order to avoid the spectral saturation.

\subsection{Theoretical calculations}

Optimized structure and force field of neutral $\mathrm{MBC}^{0}, \mathrm{BIZ}$ and IZ were calculated at $\mathrm{B} 3 \mathrm{LYP} / 6-31 \mathrm{G}^{*}$ level of theory. It has been demonstrated that this level of calculation reproduces satisfactorily the vibrational spectrum of aromatic molecules [24,25]. Geometry optimization of $\mathrm{MBC}^{0}$ has been constrained to a planar structure $\left(C_{s}\right.$ symmetry) where an intramolecular hydrogen bond occurs between the imidazolic $\mathrm{NH}$ bond and the amidic oxygen atom. This $\mathrm{MBC}^{0}$ structure agrees with the local symmetry in solid phase, providing a higher crystallinity than BIZ [26], a lower solubility in water as well as a higher melting point of $\mathrm{MBC}$ in comparison to BIZ [13]. The optimized structure of protonated and deprotonated $\mathrm{MBC},\left(\mathrm{MBC}^{+}\right.$and $\mathrm{MBC}^{-}$, respectively) and their corresponding vibrational wavenumbers have also been calculated. Fig. 1 shows the B3LYP/6-31G* optimized geometry of the MBC species and summarizes the nomenclature used for the two different $\mathrm{NH}$ bonds: imidazolic $\mathrm{NH}_{\mathrm{IZ}}$ and amidic $\mathrm{NH}_{\mathrm{AM}}$.

In addition, a simple molecular model has been assumed for the MBC-Ag surface complex involving a single silver atom linked to the three different chemical species of MBC (Fig. 2). A positive or negative silver atom has been selected depending of the negatively/neutral or positively charged $\mathrm{MBC}$ forms, respectively, in order to minimize the electrostatic repulsion between the AgNP and the adsorbate because of larger SERS enhancement is detected under this condition [27]. B3LYP method with the LanL2DZ basis set has been employed for calculating the respective optimized structures and force fields of the different complexes $\left(\mathrm{MBC}^{0}-\mathrm{Ag}^{+}\right.$, $\left.\mathrm{MBC}^{+}-\mathrm{Ag}^{-}, \mathrm{MBC}^{-}-\mathrm{Ag}^{+}\right)$. This is the same level of calculation previously used by us for analyzing the adsorption and charge transfer processes in the SERS of benzene-like molecules [28,29]. The silver cation is bonded to the imidazolic or the amidic nitrogen atoms in the optimized complexes of $\mathrm{MBC}^{0}$ or $\mathrm{MBC}^{-}$species, respectively, as occurs in heterocyclic aromatic molecules where the nitrogen atom is preferred to adsorb on the metallic surface [30,31]. In the case of $\mathrm{MBC}^{+}$, the only available interaction with silver is through the $\pi$-system of the aromatic rings given that all the nitrogen atoms are bonded to hydrogen. As expected, the $\mathrm{MBC}^{+}-\mathrm{Ag}^{+}$complex dissociates in the optimization process. Therefore, a negatively charged silver atom has been considered in order to predict the vibrational wavenumbers associated to this species $\left(\mathrm{MBC}^{+}-\mathrm{Ag}^{-}\right)$. All the calculated wavenumbers of the different complexes are real indicating that the optimized geometries correspond to equilibrium structures (Table S1 in Supplementary Material) and no scaling factor was used for the force field given that the accuracy of B3LYP vibrational wavenumbers are typically better than $95 \%$ of the experimental values [32]. All calculations have been carried out using the GAUSSIAN09 program package [33].

\section{Results and discussion}

\subsection{SERS spectra of carbendazim at different $\mathrm{pH}$}

Raman spectrum of solid MBC (Fig. S5 in Supplementary Material) has been recorded giving that the low solubility of MBC prevents recording the Raman from aqueous solutions at any $\mathrm{pH}$. This spectrum is dominated by seven strong bands recorded at $1475,1271,1262,1030,961,724$ and $618 \mathrm{~cm}^{-1}$ as well as two very strong bands at lower wavenumbers $\left(<150 \mathrm{~cm}^{-1}\right)$ which correspond to lattice vibrations. The remaining bands recorded in the $200-1800 \mathrm{~cm}^{-1}$ region show a much lower intensity than the previous ones. Table S2 (Supplementary Material) shows the vibrational assignment of MBC taking into account the B3LYP/6-31G* force field of the isolated chemical species and the reported assignment [34-39] of related molecules. The bands associated to the amidic and imidazolic $\mathrm{NH}$ bonds have been highlighted. The $1200-1300 \mathrm{~cm}^{-1}$ region is very interesting in order to recognize the presence of a particular ionized form of $\mathrm{MBC}$ given that characteristic bands of specific deprotonated species are recorded at these wavenumbers.

Figs. 3 and 4 show the medium and high wavenumber regions, respectively, of SERS spectra of $\mathrm{MBC}$ recorded at different $\mathrm{pH}$ values. All the spectra have been normalized to the corresponding strongest band, except for the weak SERS at $\mathrm{pH}=2$ which shows a very strong background. SERS at $\mathrm{pH}=6$ is almost identical to that at $\mathrm{pH}=8$ and both spectra are dominated by five strong SERS bands recorded at about 1520,1460,1270, 1230 and $1010 \mathrm{~cm}^{-1}$. However, in the SERS at $\mathrm{pH}=10$ the relative intensities of the doublets appearing at $1230 / 1270 \mathrm{~cm}^{-1}$ (Fig. 3) and $2950 / 3070 \mathrm{~cm}^{-1}$ (Fig. 4) are reversed. As a consequence, the bands at 1270 and $2950 \mathrm{~cm}^{-1}$ become the strongest ones of the respective pairs when the $\mathrm{pH}$ is basic enough. The dependence of the relative intensities of these bands on the $\mathrm{pH}$ can be related to the normal modes of the functional group which undergoes deprotonation, i.e. the amidic $\mathrm{NH}$ group, and therefore, these bands can be used to recognize which MBC chemical species (neutral or ionized) is adsorbed on the basis of the force field calculations.

\subsection{Vibrational assignment of $M B C$}

The analysis of the vibrational and SERS spectra of a complex molecular system such as MBC has been carried out on the basis of the force field calculations and the assignments of BIZ [16,34] and IZ [15,35-37] related molecules. Table S2 (Supplementary Material) correlates the experimental Raman wavenumbers of solid MBC and those of BIZ and IZ together with those calculated by using the B3LYP/6-31G* method for all the considered chemical species. Table S3 (Supplementary Material) summarizes in turn the SERS wavenumbers of $\mathrm{MBC}$ recorded at different $\mathrm{pH}$ values and the 

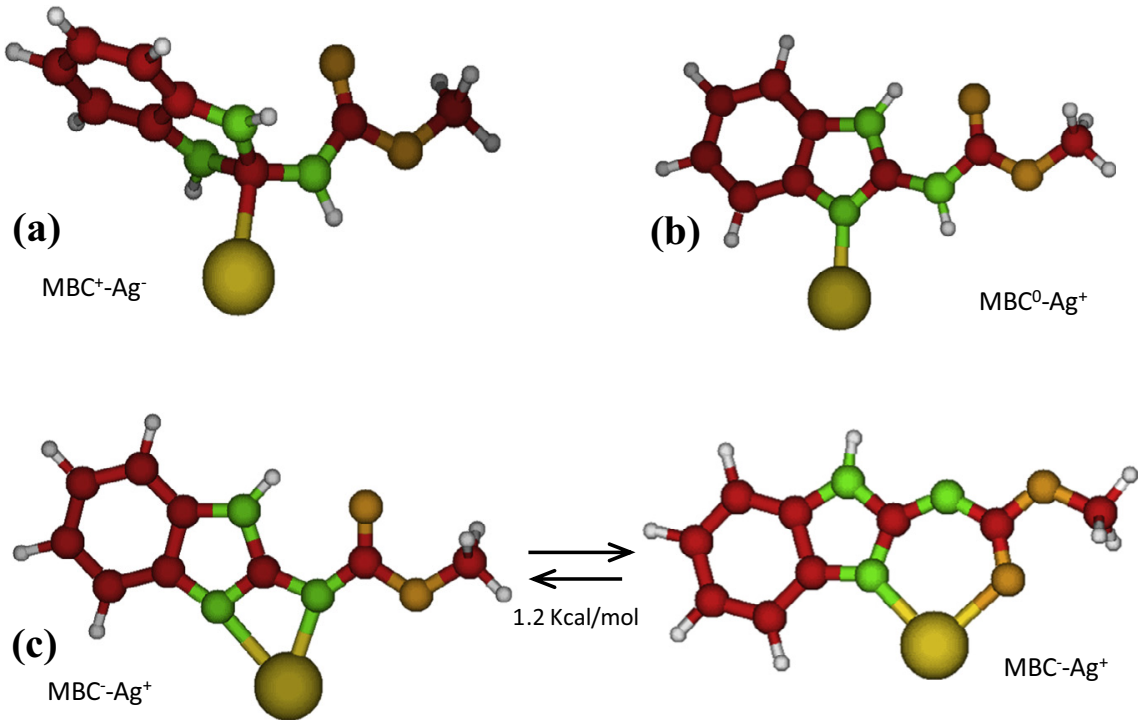

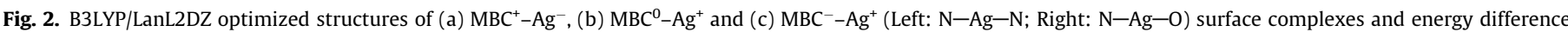

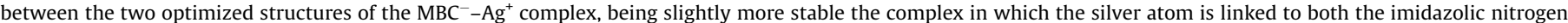
and the oxygen of the carbamate group (right).

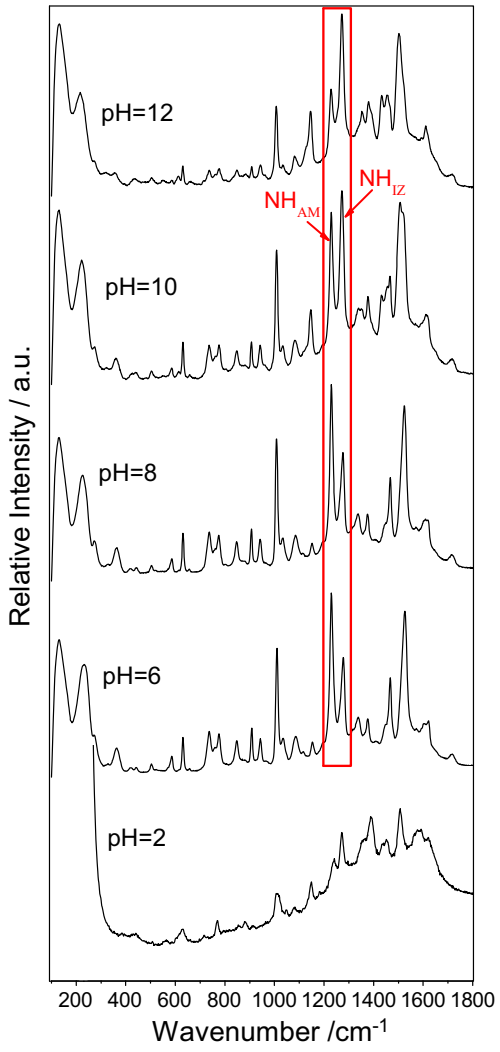

Fig. 3. SERS spectra of $\mathrm{MBC}\left(10^{-5} \mathrm{~mol} / \mathrm{L}\right)$ recorded at different $\mathrm{pH}$ values under $532 \mathrm{~nm}$ excitation.

B3LYP/LanL2DZ theoretical ones for the different MBC-Ag surface complexes.

The strongest SERS bands (Fig. 3) are assigned to in-plane normal modes and only few lines correspond to out-of-plane fundamentals. The five strong SERS bands recorded at about 1520, $1460,1270,1230$ and $1010 \mathrm{~cm}^{-1}$ at $\mathrm{pH} \geqslant 6$ are assigned to vibrational motions involving mainly $\delta \mathrm{NH}_{\mathrm{AM}}, \delta \mathrm{NH}_{\mathrm{AM}}+\delta \mathrm{CH}_{3}, \delta \mathrm{NH}_{\mathrm{Iz}}$,

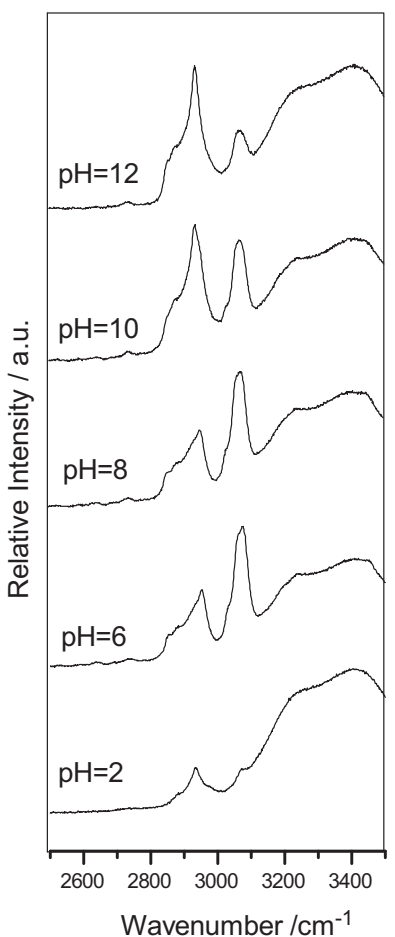

Fig. 4. High wavenumber region of SERS spectra of $\mathrm{MBC}\left(10^{-5} \mathrm{~mol} / \mathrm{L}\right)$ recorded at different $\mathrm{pH}$ values under $532 \mathrm{~nm}$ excitation.

$\delta \mathrm{NH}_{\mathrm{AM}}$ and $\delta \mathrm{CC}_{\mathrm{Bz}}$ in-plane deformations, respectively. The characteristic vibrational modes of the amide group have also been identified. Amide I vibration, recorded at about $1650 \mathrm{~cm}^{-1}$, arises mainly from the $\mathrm{C}=\mathrm{O}$ stretching coordinate, and the Amide II band, recorded at about $1550 \mathrm{~cm}^{-1}$, corresponds to a combination of the $\mathrm{NH}_{\mathrm{Am}}$ in-plane bending and the $\mathrm{CN}$ stretching coordinates. Although this last band is usually weak or absent in the Raman spectrum of polypeptides, the medium-strong SERS band observed at $1520 \mathrm{~cm}^{-1}$ can be assigned to Amide II. This band splits in two components at $\mathrm{pH}=10,1520$ and $1507 \mathrm{~cm}^{-1}$, being that recorded 
at $1520 \mathrm{~cm}^{-1}$ slightly weaker than the new one at $1507 \mathrm{~cm}^{-1}$ and, finally, becomes very weak appearing as a shoulder at $\mathrm{pH}=12$. The force field predicts one or two fundamentals in this region, depending of the considered $\mathrm{MBC}^{-}$or $\mathrm{MBC}^{0}$ species, at 1528 and $1542 \mathrm{~cm}^{-1}$ and assigned to $\mathrm{NH}_{\mathrm{IZ}}$ and $\mathrm{NH}_{\mathrm{AM}}$ in-plane deformations, respectively (Table S3, Supplementary Material). The Amide III vibration of $\mathrm{MBC}$, recorded with strong intensity at $1230 \mathrm{~cm}^{-1}$, corresponds to a combination of $\mathrm{NH}_{\mathrm{AM}}$ bending and $\mathrm{CC}$ benzenic stretching coordinates. Another strong SERS band is appearing at $1270 \mathrm{~cm}^{-1}$ which contains a large contribution from $\mathrm{NH}_{\mathrm{IZ}}$ inplane deformation.

There are also a couple of bands recorded over $1400 \mathrm{~cm}^{-1}$ showing a similar behavior to that described for the 1200 and $1500 \mathrm{~cm}^{-1}$ regions, that is, their relative intensities are reversed at basic $\mathrm{pH}$ in agreement with the proposed assignment, giving that both fundamentals are related to the $\mathrm{NH}_{\mathrm{AM}}$ and $\mathrm{NH}_{\mathrm{IZ}}$ inplane deformations.

Regarding the high wavenumber region, two broad SERS bands are recorded in all spectra at about 3400 and $3200 \mathrm{~cm}^{-1}$, respectively, where $\mathrm{NH}$ (adsorbate, Fig. 4) and $\mathrm{OH}$ (water, Figs. 4 and S4) stretching vibrations are overlapped. Two bands appear at lower wavenumbers, 3070 and $2950 \mathrm{~cm}^{-1}$, whose relative intensities are sensitive to the $\mathrm{pH}$ and showing a reverse dependence to those recorded at 1230 and $1270 \mathrm{~cm}^{-1}$. This point out to these bands should be also related to the relative abundance of the neutral and anionic species, $\mathrm{MBC}^{0}$ and $\mathrm{MBC}^{-}$respectively. We propose two alternative explanations for the dependence of their intensities on the $\mathrm{pH}$. It is possible that both bands are originated by a Fermi resonance involving a $\mathrm{CH}$ stretching fundamental and the overtone of the Amide II band (recorded, for instance at $1523 \mathrm{~cm}^{-1}$ in the SERS at $\left.\mathrm{pH}=6\left(\mathrm{MBC}^{0}, 2 \times 1523=3046 \mathrm{~cm}^{-1}\right)\right)$ as occurs in similar compounds like in proteins $[38,40]$. Another possibility is that both bands correspond to aromatic and methyl $\mathrm{CH}$ stretching vibrations which are expected to appear above and below $3000 \mathrm{~cm}^{-1}$, respectively. The relative enhancement of the band corresponding to the alkyl $\mathrm{CH}\left(2950 \mathrm{~cm}^{-1}\right)$ at higher $\mathrm{pH}$ could be due to the closer proximity of the methyl group to the metal surface in the case of the $\mathrm{MCB}^{-}-\mathrm{Ag}^{+}$complex (Fig. 2c) than in the case of the $\mathrm{MCB}^{0}-\mathrm{Ag}^{+}$complex (Fig. 2b), where the silver is displaced toward the aromatic moiety, which could be responsible for the strong intensity of the $3070 \mathrm{~cm}^{-1}$ SERS line at $\mathrm{pH}=6$.

\subsection{Adsorption of MBC on Ag nanoparticles}

The analysis of the B3LYP/LanL2DZ calculated wavenumbers of the three different $\mathrm{Ag}-\mathrm{MBC}$ surface complexes $\left(\mathrm{MBC}^{0}-\mathrm{Ag}^{+}\right.$, $\mathrm{MBC}^{-}-\mathrm{Ag}^{+}, \mathrm{MBC}^{+}-\mathrm{Ag}^{-}$, Fig. 2 and Table $\mathrm{S} 3$ ) indicates that the main changes should correspond to the fundamentals related to the ionizable imidazolic and amidic groups. Generally speaking, the interaction of the imidazole ring with the surface seems to dominate the adsorption of $\mathrm{MBC}$ on silver, even in the case of neutral $\mathrm{MBC}^{0}$, as pointed out by the calculated fundamentals at 1027 and $1363 \mathrm{~cm}^{-1}$ of the complex with $\mathrm{Ag}^{+}$.

In addition, most of the enhanced bands in the SERS spectrum, such as those recorded at ca. $1520,1270,1230$ and $1010 \mathrm{~cm}^{-1}$, correspond to in-plane normal modes of aromatic rings what suggests a perpendicular orientation of the benzimidazolic ring with respect to the metallic surface on the basis of the propensity rules of the EM enhancement mechanism of SERS [41]. Although some of the single bonds related to the carbamate group could rotate more or less freely (giving "non-planar" conformations), the presence of a hydrogen bond in the carbamate (see Fig. $2 b$ and c), the resonance in the amide group and the bonding with the silver favors a $C_{s}$ structure with perpendicular orientation of the adsorbate. Only internal rotations along the $\mathrm{C}-\mathrm{O}\left(\mathrm{CH}_{3}\right)$ and $\mathrm{O}-\mathrm{CH}_{3}$ single bonds are expected. In addition, B3LYP/LanL2DZ calculations predict a molecular structure for $\mathrm{MBC}^{0}-\mathrm{Ag}^{+}$and the two conformers of $\mathrm{MBC}^{-}-\mathrm{Ag}^{+}$with $\mathrm{C}_{\mathrm{s}}$ symmetry in which two equivalent methyl hydrogens lie above and below the symmetry plane (Table S1 in Supplementary Material).

The chemical species adsorbed on the silver surface can be checked by analyzing the dependence on the $\mathrm{pH}$ of the relative SERS intensities of the pairs of the bands assigned to amidic/imidazolic groups. The most striking feature is the behavior of the bands recorded at $1230 / 1270 \mathrm{~cm}^{-1}$ and assigned to $\mathrm{NH}_{\mathrm{AM}}$ and $\mathrm{NH}_{\mathrm{IZ}}$ inplane deformations, respectively, where the relative intensity of the $1230 \mathrm{~cm}^{-1}$ line decreases when $\mathrm{pH}$ increases, while the $1270 \mathrm{~cm}^{-1}$ band becomes in turn stronger. There are also other bands sensitive to the $\mathrm{pH}$ recorded in the 1300 and $1400 \mathrm{~cm}^{-1}$ region as, for instance, the bands assigned to the amidic group (1340 and $1460 \mathrm{~cm}^{-1}$ ) that become weaker than the assigned to imidazolic group (1380 and $1430 \mathrm{~cm}^{-1}$ ) when the $\mathrm{pH}$ is raised. The same occurs in the $1500 \mathrm{~cm}^{-1}$ region. The band recorded at $1522 \mathrm{~cm}^{-1}$ (amidic group) shows a shoulder at $1505 \mathrm{~cm}^{-1}$ (imidazolic group) in the SERS at $\mathrm{pH}=10$ and dominates at $\mathrm{pH}=12$. These results indicate that the $\mathrm{MBC}^{0}$ and $\mathrm{MBC}^{-}$chemical species are adsorbed on the nanoparticles and that the $\mathrm{MBC}^{+}$species is not able to interact with the surface. The imidazolic $\mathrm{N}$ atom is involved in the adsorption process and only when $\mathrm{MBC}^{0}$ species is present in the sol $(\mathrm{pH}>6)$ an enhancement of SERS intensity is observed. This is also observed in the VIS spectra of MBC colloidal solutions measured at different pH (Fig. 5). A new band at high wavelength $(\approx 780 \mathrm{~nm})$, and characteristic of aggregation, appears in the spectra at $\mathrm{pH}>6$, indicating that the adsorption of MBC on AgNPs is only effective when the pesticide is in neutral or anionic forms, thus corroborating that the IZ group is involved in the interaction with the metal. These evidences, together with the absence of any SERS band recorded at ca. $1295 \mathrm{~cm}^{-1}$ which is assigned to $\mathrm{NH}$ deformation of the protonated imidazolic nitrogen (see Table S3), corroborates that $\mathrm{MBC}^{0}$ or $\mathrm{MBC}^{-}$species originate the SERS.

This conclusion is further supported by the attempts to calculate the optimized B3LYP/LanL2DZ geometry of the $\mathrm{MBC}^{+}-\mathrm{Ag}^{+}$. These calculations do not converge to any minimum given that the $\mathrm{MBC}^{+}$cation does not have any free nitrogen atom able to interact with the metallic surface. Only an optimized geometry for the $\mathrm{MBC}^{+}-\mathrm{Ag}^{-}$complex has been obtained where the negatively charged silver atom is located above the aromatic ring (see Fig. 2a). In this case, the $\mathrm{MBC}^{+}$looses the planarity because of the imidazolic carbon pyramidalizes while the silver anion is located above the three nitrogen atoms. This kind of interaction would give rise to the enhancement of SERS bands corresponding to the

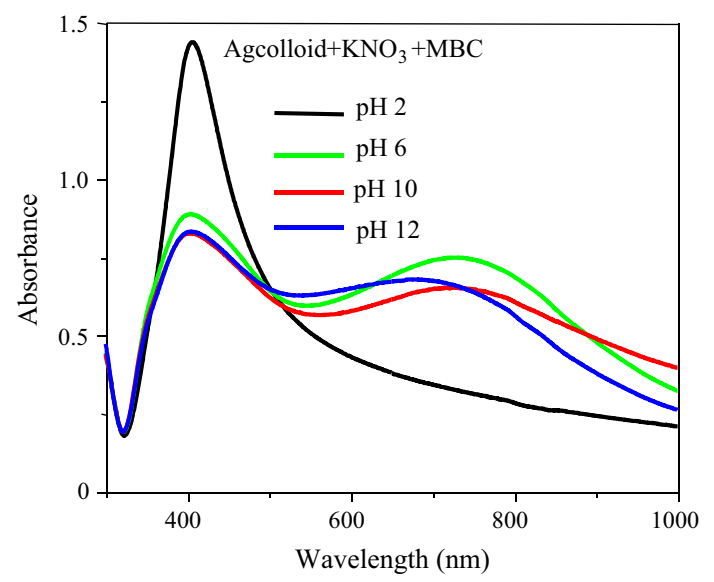

Fig. 5. UV-Vis absorption spectra of $\mathrm{Ag}$ sols with $\mathrm{KNO}_{3}$ and $\mathrm{MBC}$ at different $\mathrm{pH}$ values. 
out-of-plane normal modes of the aromatic rings [41] but no bands assigned to these vibrations are enhanced, what discards the adsorption of the cationic $\mathrm{MBC}^{+}$species.

Therefore, $\mathrm{MBC}^{0}$ and its amidate anion $\mathrm{MBC}^{-}$are the two chemical species adsorbed on the metallic surface. The optimized structure of the $\mathrm{MBC}^{0}-\mathrm{Ag}^{+}$complex yields a planar geometry with $\mathrm{C}_{\mathrm{s}}$ symmetry, where the silver atom is bonded to the imidazolic nitrogen atom giving a perpendicular orientation of the benzimidazolic ring with respect to the metallic surface (Fig. 2b). The calculated vibrational wavenumbers for this complex are in agreement with the experimental ones. The $\mathrm{MBC}^{-}$species contains the amidate group and can be adsorbed through either the imidazolic and the amidic nitrogen atoms $(\mathrm{N}-\mathrm{Ag}-\mathrm{N})$, or the imidazolic nitrogen and the carbonyl oxygen atom $(\mathrm{N}-\mathrm{Ag}-\mathrm{O})$ as show the corresponding optimized structures (Fig. 2c). The calculated force fields for both metallic complexes predict very similar wavenumbers in agreement with the experimental results and the energy difference between these two structures is very small $(1.2 \mathrm{kcal} / \mathrm{mol})$, being the last complex slightly more stable.

As a result from the analysis of the vibrational assignment based on the force field calculations (Table S3) it can be concluded that the 1230 and $1270 \mathrm{~cm}^{-1}$ SERS bands are characteristic of the neutral and ionic $\mathrm{MBC}^{0} / \mathrm{MBC}^{-}$species, respectively, as the respective dependence of their intensities on the $\mathrm{pH}$ shows. In this respect, we have found a linear correlation between the intensity ratio of these SERS bands $I_{1230} / I_{1270}$ (measured from their peak heights) and the $\mathrm{pH}$ as shows Fig. 6 what allows for predicting (at least roughly) macroscopic $\mathrm{pH}$ value of the solution from the relative intensities of both bands. This linear dependence has been already observed in molecules that show an ionizable group and a surface interacting center, what allows for using them as $\mathrm{pH}$ sensor [42]. On the contrary, simple carboxylic acids or amides are no valid pH SERS-sensors because the ionizable chemical group is also involved in the linkage with the metal [18].

\section{Conclusions}

The identification of the chemical species of MBC adsorbed on $\mathrm{Ag}$ nanoparticles has been carried out on the basis of DFT quantum mechanical calculations and by analyzing the dependence of the SERS spectra on the $\mathrm{pH}$. A complete vibrational assignment of all the possible chemical species adsorbed on the silver surface has been proposed. The SERS active forms correspond to the neutral $\mathrm{MBC}$ and its amidate ion $\left(\mathrm{MCB}^{-}\right)$with a perpendicular orientation of the benzimidazolic ring with respect to the metallic surface, given that no out-of-plane bands are enhanced in SERS. The

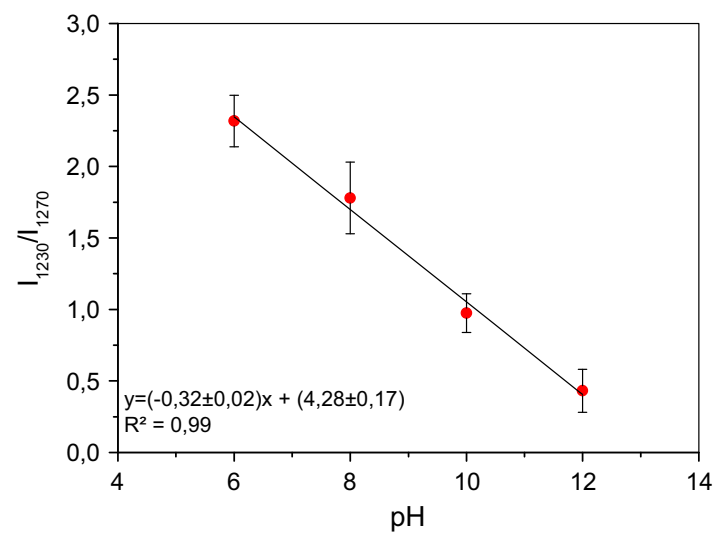

Fig. 6. Dependence of the relative intensity of the SERS bands recorded at 1230 and $1270 \mathrm{~cm}^{-1}$ on the $\mathrm{pH}$. changes in the intensities of the pairs or SERS bands recorded in the $1200 \mathrm{~cm}^{-1}$ and $3000 \mathrm{~cm}^{-1}$ regions when the $\mathrm{pH}$ is raised evidence the relative concentration of neutral/amidate species. Moreover, theoretical results point out that the MBC coordination to $\mathrm{Ag}$ surface is monodentate through the imidazolic nitrogen atom in neutral MBC species and bidentate through both imidazolic and amidic nitrogen atoms or the oxygen atom of the amidate group in $\mathrm{MBC}^{-}$anionic species. Finally a linear dependence between the relative intensity of the $1230 / 1270 \mathrm{~cm}^{-1}$ bands on the $\mathrm{pH}$ has been found because of the amide group is not involved in the adsorption process.

\section{Acknowledgments}

We are grateful to the Spanish MINECO (CTQ2012-31846, FIS2014-52212-R) and Junta de Andalucía (FQM-5156 and 6778), and to the Brazilian agencies CAPES, CNPq and FAPESP, for financial support. The authors thank to SCAI and Rafael Larrosa (UMA) for computational facilities.

\section{Appendix A. Supplementary material}

Fig. S1 shows the resonance structures of $\mathrm{MBC}^{+}$and $\mathrm{MBC}^{-}$ions, and Figs. S2-S4 correspond to the SEM image of AgNPs, UV-Vis spectra of colloid, pre-aggregated colloid and aggregated with the adsorbate $\mathrm{MBC}$, and the Raman spectra of pre-aggregated colloid at different $\mathrm{pH}$, respectively. Fig. S5 shows the Raman spectrum of solid MBC. Table S1 summarizes the Cartesian coordinates of the different complexes and Tables S2 and S3 summarize in turn the experimental (Raman and SERS) and theoretical DFT vibrational wavenumbers of $\mathrm{BIZ}, \mathrm{IZ}$ and $\mathrm{MBC}$ and the calculated silver complexes. Supplementary data associated with this article can be found, in the online version, at http://dx.doi.org/10.1016/j.jcis. 2015.11.045.

\section{References}

[1] Y. Tang, F. Zhang, S. Hu, Z. Cao, Z. Wu, W. Jing, Corros. Sci. 74 (2013) 271.

[2] S. Bhattacharya, P. Chaudhuri, Curr. Med. Chem. 15 (2008) 1762.

[3] M. Lezcano, W. Al-Soufi, M. Novo, E. Rodríguez-Núñez, J.V. Tato, J. Agric. Food Chem. 50 (2002) 108.

[4] H.S. Zhu, L.H. Wu, R.B. Li, L.A. Xia, J.Q. Han, Q.J. Zhang, Y.C. Bian, Q.R. Yu, Anal. Chim. Acta 619 (2008) 165.

[5] N. Ni, T. Sanghvi, S.H. Yalkowsky, Int. J. Pharm. 244 (2002) 99.

[6] M. Pozo, L. Hernández, C.A. Quintana, Talanta 81 (2010) 1542.

[7] T. Vo-Dinh, J. Fetzer, A.D. Campliglia, Talanta 47 (1998) 943.

[8] L.N. Furini, S. Sanchez-Cortes, I. López-Tocón, J.C. Otero, R.F. Aroca, C.J.L. Constantino, J. Raman Spectrosc. (2015), http://dx.doi.org/10.1002/jrs.4737.

[9] I. López-Tocón, J.C. Otero, J.F. Arenas, J.V. Garcia-Ramos, S. Sanchez-Cortes, Anal. Chem. 83 (2011) 2518.

[10] M. Moskovits, Rev. Mod. Phys. 57 (1985) 783.

[11] R. Aroca, Surface-Enhanced Vibrational Spectroscopy, John Wiley \& Sons, Chichester, U.K., 2006.

[12] L. Guerrini, J.V. Garcia-Ramos, C. Domingo, S. Sanchez-Cortes, Anal. Chem. 81 (2009) 1418.

[13] P. Leyton, S. Sánchez-Cortes, J.V. Garcia-Ramos, C. Domingo, M. CamposVallette, C. Saitz, R.E. Clavijo, J. Phys. Chem. B 108 (2004) 17484.

[14] A.K. Ojha, Chem. Phys. 340 (2007) 69.

[15] B.H. Loo, Y. Tse, K. Parsons, C. Adelman, A. El-Hage, Y.G. Lee, J. Raman Spectrosc. 37 (2006) 299.

[16] M.S. Kim, M.K. Kim, C.J. Lee, Y.M. Jung, M.S. Lee, Bull. Korean Chem. Soc. 30 (2009) 2930.

[17] D.S. Kellogg, J.E. Pemberton, J. Phys. Chem. 91 (1987) 1120.

[18] J.L. Castro, M.R. Lopez-Ramirez, J.F. Arenas, J. Soto, J.C. Otero, Langmuir 28 (2012) 8926.

[19] A. Streitwieser, C.H. Heathcock, E.M. Kosower, Introduction to Organic Chemistry, Prentice-Hall, 1998.

[20] L. Guerrini, J.V. Garcia-Ramos, C. Domingo, S. Sanchez-Cortes, Anal. Chem. 81 (2009) 953.

[21] N. Leopold, B. Lendl, J. Phys. Chem. B 107 (2003) 5723.

[22] M.V. Cañamares, J.V. Garcia-Ramos, J.D. Gómez-Varga, C. Domingo, S. SanchezCortes, Langmuir 21 (2005) 8546.

[23] A.M. El Badawy, T.P. Luxton, R.G. Silva, K.G. Scheckel, M.T. Suidan, T.M. Toloymat, Environ. Sci. Technol. 44 (2010) 1260. 
[24] L. Bencivenni, F. Ramondo, V. Pieretti, N. Sanna, J. Chem. Soc. Perkin Trans. 2 (2000) 1685.

[25] G.A. Giffin, G.A. Boesch, D.N. Bopege, D.R. Powell, R.A. Wheeler, R. Frech, J. Phys. Chem. B 113 (2009) 15914.

[26] C.J. Dik-Edixhoven, H. Schent, H. Van der Meer, Cryst. Struct. Commun. 2 (1973) 23.

[27] R.A. Alvarez-Puebla, E. Arceo, P.J.G. Goulet, J.J. Garrido, R.F. Aroca, J. Phys. Chem. B 109 (2005) 3787.

[28] S.P. Centeno, I. López-Tocón, J. Roman-Perez, J.F. Arenas, J. Soto, J.C. Otero, J. Phys. Chem. C 116 (2012) 23639.

[29] F. Avila, D.J. Fernandez, J.F. Arenas, J.C. Otero, J. Soto, Chem. Commun. 47 (2011) 4210

[30] J. Soto, D.J. Fernández, S.P. Centeno, I. López Tocón, J.C. Otero, Langmuir 18 (2002) 3100.

[31] M. Sardo, C. Ruano, J.L. Castro, I. López-Tocón, J. Soto, P. Ribeiro-Claro, J.C. Otero, Phys. Chem. Chem. Phys. 11 (2009) 7437.

[32] Z.Q. Cai, Y.X. Zhu, Y. Zhang, Spectrochim. Acta, Part A 69 (2008) 130.

[33] M.J. Frisch, G.W. Trucks, H.B. Schlegel, G.E. Scuseria, M.A. Robb, J.R. Cheeseman, G. Scalmani, V. Barone, B. Mennucci, G.A. Petersson, H. Nakatsuji, M. Caricato, X. Li, H.P. Hratchian, A.F. Izmaylov, J. Bloino, G. Zheng, J.L. Sonnenberg, M.
Hada, M. Ehara, K. Toyota, R. Fukuda, J. Hasegawa, M. Ishida, T. Nakajima, Y. Honda, O. Kitao, H. Nakai, T. Vreven, J.A. Montgomery Jr., J.E. Peralta, F. Ogliaro, M. Bearpark, J.J. Heyd, E. Brothers, K.N. Kudin, V.N. Staroverov, R. Kobayashi, J. Normand, K. Raghavachari, A. Rendell, J.C. Burant, S.S. Iyengar, J. Tomasi, M. Cossi, N. Rega, J.M. Millam, M. Klene, J.E. Knox, J.B. Cross, V. Bakken, C. Adamo, J. Jaramillo, R. Gomperts, R.E. Stratmann, O. Yazyev, A.J. Austin, R. Cammi, C. Pomelli, J.W. Ochterski, R.L. Martin, K. Morokuma, V.G. Zakrzewski, G.A. Voth, P. Salvador, J.J. Dannenberg, S. Dapprich, A.D. Daniels, Ö. Farkas, J.B. Foresman, J.V. Ortiz, J. Cioslowski, D.J. Fox, Gaussian 09, Revision D.01, Gaussian, Inc., Wallingford CT, 2009.

[34] M.A. Morsy, M.A. Al-Khaldi, A. Suwaiyan, J. Phys. Chem. A 106 (2002) 9196.

[35] C.M. Yoshida, T.B. Freedman, T.M. Loehr, J. Am. Chem. Soc. 97 (1975) 1028.

[36] D.A. Carter, J.E. Pemberton, Langmuir 8 (1992) 1218.

[37] M. Majoube, M. Henry, L. Chinsky, P.Y. Turpin, Chem. Phys. 169 (1993) 231

[38] S. Krimm, J. Bandekar, Adv. Protein Chem. 38 (1986) 181.

[39] A. Barth, C. Zscherp, Quart. Rev. Biophys. 35 (2002) 369.

[40] J. Bellanato, J. Spectrochim. Acta 16 (1960) 1344.

[41] M. Moskovits, D.P. DiLella, K.J. Maynard, Langmuir 4 (1988) 67.

[42] S.W. Bishnoi, C.J. Rozell, C.S. Levin, M.K. Gheith, B.R. Johnson, D.H. Johnson, N.J. Halas, Nano Lett. 6 (2006) 1687. 